\title{
Identifying households with low immunisation completion in Bangladesh
}

\author{
Johanna Andrews-Chavez ${ }^{1}$, Animesh Biswas ${ }^{2}$, Mervyn Gifford ${ }^{3}$, Charli Eriksson ${ }^{2}$, \\ Koustuv Dalal $^{\text {2\# }}$ \\ ${ }^{1}$ Friedman School of Nutrition Science and Policy, Tufts University, Boston, USA \\ ${ }^{2}$ Department of Public Health Sciences, School of Health and Medical Sciences, Örebro University, Örebro, Sweden; \\ "Corresponding Author: koustuv2010@hotmail.com \\ ${ }^{3}$ Department of Public Health Sciences, University of Skövde, Skövde, Sweden
}

Received 26 June 2012; revised 10 August 2012; accepted 1 September 2012

\begin{abstract}
The objective of this study was to investigate if the mothers' demographics and household characteristics-including type of use of cooking fuel, energy and toilet facilities - have any implication for complete immunisation rates among their children. A cross-sectional data analysis of a nationally representative sample of 4925 women with at least one child was performed. Chi-squared tests and multivariate logistic regression analyses were used. Immunisation coverage was positively associated with the mother's education and with household characteristics such as toilet facility, electricity and involvement in a microfinance group. These findings indicate the need for further advocacy for increased knowledge on the importance of vaccination and affordable public immunisation programs focusing on higher risk households such as those with pit facilities, lack of electricity and no participation in a microfinance group. Such households warrant further attention and can be targeted for immunisation coverage.
\end{abstract}

Keywords: Bangladesh; Children; Household Characteristics; Vaccination Completion

\section{INTRODUCTION}

Child immunisation is one of the most successful strategies for reducing child illness and mortality. It is one of the most efficient ways of protecting the health of women and children around the world against contemporary diseases that can be both burdensome and deadly [1]. Immunisation of children under one year of age against the six major vaccine preventable diseases: tu-

${ }^{*}$ Conflict of interest: declared none. berculosis, diphtheria, pertussis, tetanus, poliomyelitis, and measles, is one of the most cost-effective strategies to reduce both infant and child morbidity and mortality. A recent estimate suggests that immunisation programs prevent 3.2 million deaths annually [2]. Although child immunisation is a cost-effective public health strategy [3, 4], incomplete vaccinations still exist and the factors related with incomplete immunisations are poorly understood. In Bangladesh, the high density of the population, along with poverty contributes significantly to health issues [5]. The Expanded Program for Immunisation (EPI) of the World Health Organization (WHO) was created in 1974 as a worldwide alliance to expand immunisation services and coverage [4]. In 1979 Bangladesh launched EPI to combat 6 major childhood diseases - polio, measles, pertussis, tetanus, diphtheria and tuberculosis, yet the program did not take-off until 1985 when Bangladesh made the commitment to reach child immunisation by 1990 [4,6]. The Bangladeshi national budget includes a line item to purchase routine immunisation programme vaccines; in 2009 almost half (40\%) of all spending on routine immunisation was financed with government funds [7]. The program managed to increase vaccination rates from $2 \%$ coverage in 1985 to $61 \%$ coverage in 1991 and the coverage continued to improve thereafter $[7,8]$. In Bangladesh measles vaccination rates tend to be lower, possibly because the incidence of measles has declined over the last three decades and complacency has grown regarding the measles vaccination [9]. Although achievement of the immunisation program in Bangladesh has been impressive and the WHO's health profile showed high rates of immunisation in 1998 (BCG coverage was at $96.8 \%$, measles at $96 \%$, DPT3 at $95 \%$, and oral polio at $92 \%$ ), the coverage of fully immunised children (all doses given at the correct intervals) was only $71 \%[10,11]$. A similar study in $\mathrm{Ni}-$ geria found that $61.9 \%$ children were under complete immunisation coverage, while the coverage level was 
higher in rural community (81\%) against DPT/OPV [3]. Another study conducted by Jha et al. in Nepal found that immunisation rates were $65.7 \%$ [12]. A child is said to be fully immunised if he or she has received all of the following vaccines: a dose of Bacille Calmette Guerin (BCG), three doses of oral polio (OPV), three doses of diphtheria, pertussis and tetanus (DPT), three doses of Hepatitis B (HB) and one dose of measles [3]. For certain vaccines, the first dose does not provide complete immunity, hence more than one dose is necessary in order to build more complete immunity. Both correct timing and spacing of vaccine doses are essential to adequate vaccine administration. By decreasing the intervals between dosages, the vaccine's antibody response may be interrupted $[13,14]$.

In spite of the success of this immunisation program, some significant challenges still remain. Studies found that coverage is lowest for DPT3, Polio3 and measles in rural areas [15-17]. The acceptance of these vaccinations has increased but levels of full immunisation coverage are less than satisfactory and can be improved. Moreover, there are still large variations among different levels of education and socio-economic factors (electricity, toilet facility, microfinance and cooking fuel), leaving room for new policies targeting more equitable coverage. A study conducted by Chowdhury and colleagues found that immunisation coverage was higher for children whose mothers were more educated [17]. Other studies also reported a strong relationship between child mortality and maternal education $[18,19]$. Odusanya et al. identified that completeness of vaccination significantly correlated with knowledge of mothers on immunisation [3]. A study by Sanou et al. showed that in rural areas, children from Muslim families had lower immunisation coverage rates compared to others and that religion was not significantly related to lower immunisation coverage in urban areas [20]. Similarly, a study in India by Nath et al. showed that Muslim religion was a significant independent predictor of partial immunisation status of the child and that Muslim religion was associated with the unimmunised status of the child [21,22].

In Bangladesh, poor households depend heavily on wood, dung and other biomass fuels for cooking [23]. Studies found that solid cooking fuels remain the principal household fuel for around 3 billion people [24,25]. Since the use of solid cooking fuels is closely linked to poverty, it is also linked with generally poor access to health care [24]. In order to overcome the reasons for incomplete immunisation we must identify the household characteristics most strongly associated with delayed or non-immunisation (low acceptance of immunisations) of their children. This paper examined whether the effects of these variables were different for children in households with type of cooking fuel use, use of electricity, type of toilet use, association with microfinance groups and mothers' social, economic, demographic, and regional characteristics.

\section{METHODS}

This study was a secondary analysis from the fifth and latest Bangladesh Demographic and Health Survey (BDHS, 2007), a nationally representative household survey using a structured questionnaire [5]. There were 10,996 women, aged 15 - 49 years old, surveyed from 10,400 households.

The survey involved multistage cluster sampling and was based on the 2001 population census enumeration areas (EAs) with population and household information. EAs were used as primary sampling units (PSUs) for the whole survey. Each PSU had 100 households with locational maps and geographical boundaries. In total 361 PSUs (227 in rural areas and 134 in urban areas) were randomly selected from the six divisions - Barisal, Chittagong, Dhaka, Khulna, Rajshahi and Sylhet. During January to March 2007, a household listing operation was carried out in all PSUs. In the next part, 30 households were selected from each PSU, using an equal probability systematic sampling technique in relation to the 2001 population census. Finally 10,819 households were initially selected from the sample clusters for the survey.

All ever-married women of reproductive age (15 - 49 years) who slept in the chosen households the night before the survey were eligible to participate in the survey. In the end, 10,400 households were selected for the study. From these selected households, 11,178 eligible women aged 15 - 49 years were identified and 10,996 were interviewed. There was a response rate of $98 \%$. In the current study women $(\mathrm{N}=6150)$ with at least one child were included. For the purpose of this study, a limited number of available DHS variables expected to contribute to identifying households with low immunisation coverage were chosen.

Immunisations: Mothers were asked in a retrospective manner whether her children were immunised (BCG, Measles, DPT1, DPT2, DPT3, Polio1, Polio2, Polio3) and they were asked to show their vaccination card to the interviewer. The response validated by vaccination card was included in our study.

Cooking fuel: Respondents were asked whether they used solid cooking fuel (biomass fuels such as wood, charcoal, dung or straw) or non-solid cooking fuels (kerosene, LPG/natural gas, or electricity).

Age of the respondents in 7 age groups: 15 - 19, 20 24, 25 - 29, 30 - 34, 35 - 39, 40 - 44 and 45 - 49. Place of residency: rural or urban. Education: No education, primary education, secondary education and higher educa- 
tion. Religion: Muslim and others. Economic status: wealth index constructed from data on all household assets. Rustein et al. developed this as an indicator to measure the level inequalities in household income, use of health services, and health outcomes [26]. Wealth index has five quintiles: poorest, poorer, middle, richer and richest. Divisions: Bangladesh has six administrative divisions: Barisal, Chittagong, Dhaka, Rajshahi, Sylhet, and Khulna. Microfinance: yes or no. Type of Toilet Facility: flush, pit or no facility. Electricity: yes or no.

Place of delivery: Respondents were asked whether they had their delivery at home (either their own or someone else's), or at health care facilities (private health facility, public health facility or somewhere with medical delivery facilities).

Prevalence estimates were calculated to reflect acceptance of BCG, measles, DPT and polio vaccinations. The vaccinations were the dependent variables. The proportions and chi-square test were used to examine the cross-relationships between dependent (vaccinations) and independent variables (demographics). Multivariate logistic regressions were employed to study the potential association between target variables such as vaccinations with independent demographic variables.

Also a separate variable was constructed where children had no vaccination at all and a multivariate logistic regression analysis was used with that variable. Proportions of non-immunised children in all primary sampling units (PSUs) were presented in bar-diagram in all the six administrative divisions by rural and urban areas. Initially all PSUs were extracted from GPS base of the BDHS. Then non-immunisation variable was matched to each PSU. Finally, proportions of non-immunised children in each division were estimated in rural and urban areas.

Confidence intervals (CI) were measured at 95\% level. Data were analysed using SPSS version 18.0.

The survey received ethical approval from the Institutional Review Board of Opinion Research Corporation (ORC), Macro International Incorporated. Informed consent was obtained from the participants prior to the interview, and the right to withdraw was emphasised throughout the survey.

\section{RESULTS}

Table 1 shows among the women surveyed $(n=6150)$ the majority (circa 91\%) used solid cooking fuel. Almost half of the respondents (47\%) had electricity at home. The majority of them (48\%) used pit toilets, $24 \%$ used flush toilets, while $28 \%$ of the respondents had no toilet facilities. Around $80 \%$ of households with electricity used solid fuels to cook. Table 2 shows that $93 \%$ of children received $\mathrm{BCG}$ and $71 \%$ of children received the measles vaccine. DPT1 had been received by $92 \%$, DPT 2 by $87 \%$ and DPT 3 by $81 \%$ of children. The Polio 1 vaccine had been received by $94 \%$, Polio 2 by $89 \%$ and Polio3 by $83 \%$ of children.

Approximately $80 \%$ of Dhaka residents used solid cooking fuel, while around $90 \%$ of residents in other divisions used solid fuel to cook. Findings showed that a wide gap in vaccination coverage still exists between urban and rural areas. People who lived in urban areas used significantly less amount of solid cooking fuel than those who lived in rural areas, $75 \%$ and $99 \%$ respectively. There is an inverse trend with education and solid cooking fuel use. As education levels rise, the use of solid cooking fuel decreases. Participants who were part of a microfinance group were more likely to use solid cooking fuels. Likewise with education we found an inverse relationship between economic status and use of solid cooking fuel. As wealth increases, use of solid cooking fuel significantly decreases.

Barisal and Sylhet had the lowest electricity rates. Seventy six percent of people who live in urban areas had electricity, compared with $32 \%$ in rural areas. Use of electricity increased as education increased and less than half of those participating in a microfinance group had electricity.

People residing in Barisal were the least likely to have a flush toilet. Significant associations were found between flush toilet facilities and demographics. Forty seven percent of the respondents living in urban areas had a flush toilet, compared with $13 \%$ living in rural areas. There was a positive relationship between education and flush toilet facilities; as education increased the likelihood of having a flush toilet increased. As wealth increased, so did the probability of having a flush toilet.

Significant associations were found among and between the divisions in Bangladesh and vaccination coverage. Rates of measles vaccinations among children in Bangladesh are still low. Overall, only $71 \%$ of children received the measles vaccine. As doses increased, the percentage of children receiving the DPT and polio vaccines decreased. Sylhet and Chittagong had lower vaccination coverage than Barisal, Dhaka, Khulna and Rajshahi. Urban Dhaka (27.7\%), rural Chittagong (23.6\%) and rural Shyllet $(23 \%)$ demonstrated highest percentage of non-vaccinated children according to distribution of non-immunised children in PSUs (Figure 1). On the other hand, rural Khulna (7.2\%) and urban Barisal (9.4\%) had the lowest proportion of non-immunised children. The mother's education was a very important predictor of the child's immunisation coverage. For almost all the vaccines, $90 \%$ of children from mothers with secondary or higher education showed vaccination coverage.

There was a strong association between type of toilet facility and vaccination acceptance. Children in the 


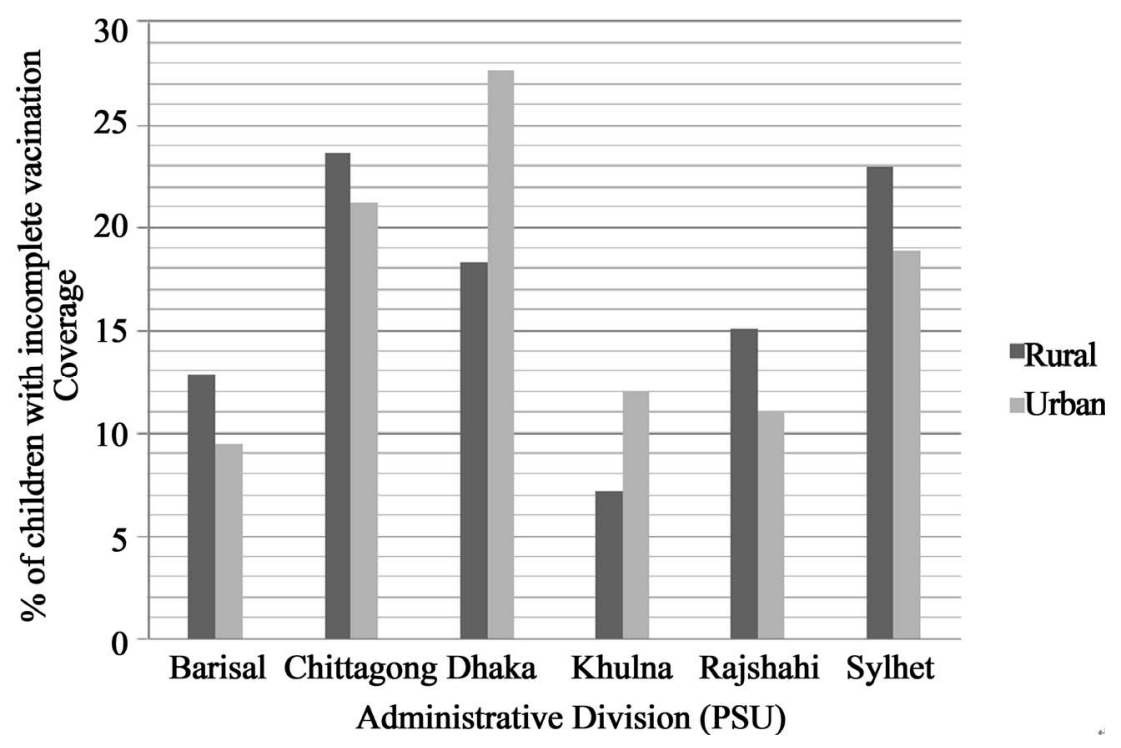

Figure 1. Incomplete vaccination coverage for children by administrative division (urban \& rural PSUs*).

households without facilities (no flush toilet or pit) had lower rates of vaccination than those with facilities (Table 2). For DPT, $75 \%$ of children in the households without a toilet facility were vaccinated, while $84 \%$ of those in a household with a flush or pit toilet were vaccinated. Similar results were observed with BCG, measles and Polio3. Households with electricity had better immunisation coverage of their children. For the measles, DPT 2 and DPT 3 vaccines we found $8 \%-12 \%$ more coverage in the households with electricity. Significant associations between microfinance and vaccination coverage were also found. Those who participated in a microfinance group were more likely to be vaccinated against all the vaccines included in this study. Strong positive associations were found between wealth and acceptance of vaccines. As wealth increased, vaccination coverage increased in all cases, except measles. Measles coverage was $87 \%$ for the poorest group, $67 \%$ for the second poorest group and $75 \%$ for the richest group.

In addition to the strong association with the aforementioned variables, a strong association was found between choice of cooking fuel and vaccination coverage. Households using non-solid cooking fuel had a higher proportion of vaccinated children. Around $76 \%$ of children in households using non-solid cooking fuel were vaccinated for measles in comparison to only $70 \%$ of those that used solid fuels. For households using solid cooking fuel, $81 \%$ of children were fully vaccinated for DPT and $82 \%$ were fully vaccinated for polio. Place of delivery emerged as an important factor for predicting immunisation of the children. Mothers who delivered at home had less immunisation coverage of their children than women who delivered at health care facilities.
Results of the multivariate analysis for individual vaccine dosages are presented in Table 3. Among the independent variables, residency, education, type of toilet, electricity, microfinance and cooking fuel showed statistically significant associations with acceptance of immunisation. Rural residents were more likely to be fully vaccinated with DPT3 and Polio3.

A significant positive association was found between education and vaccine acceptance. Women with no education or a primary education had lower odds of having vaccinated their children against BCG. Children of women with the highest education had twice the odds of being vaccinated for measles than children of mothers with no education $\{\mathrm{OR}=0.5 ; \mathrm{p}<0.001\}$. Women in the two lowest education categories had lower odds of fully vaccinating their children against $\mathrm{DPT}\{\mathrm{OR}=0.33 ; \mathrm{p}<$ $0.001\}$ and $\{\mathrm{OR}=0.48 ; \mathrm{p}<0.001\}$ and polio $\{\mathrm{OR}=$ $0.34 ; \mathrm{p}<0.001\}$ and $\{\mathrm{OR}=0.45 ; \mathrm{p}<0.001\}$, respectively.

Households with a pit as a main toilet facility had twice the odds of having their children vaccinated than those with no facility $\{\mathrm{OR}=1.75 ; \mathrm{p}<0.001\}$ for the BCG vaccine, $\{\mathrm{OR}=1.61 ; \mathrm{p}<0.001\}$ for DPT3 and $\{\mathrm{OR}=1.68 ; \mathrm{p}<0.001\}$ for Polio3. Electricity was also found to have a positive association with vaccination rates. Children living in households without electricity had lower odds of being vaccinated against $\mathrm{BCG}\{\mathrm{OR}=$ $0.64 ; \mathrm{p}<0.001\}$, measles $\{\mathrm{OR}=0.72 ; \mathrm{p}<0.001\}$, DPT3 $\{\mathrm{OR}=0.66 ; \mathrm{p}<0.001\}$ and Polio3 $\{\mathrm{OR}=0.64 ; \mathrm{p}<$ $0.001\}$.

Members of microfinance groups had higher odds of vaccinating their children. Those who were not members had lower rates of $\mathrm{BCG}\{\mathrm{OR}=0.62 ; \mathrm{p}<0.001\}$, measles 


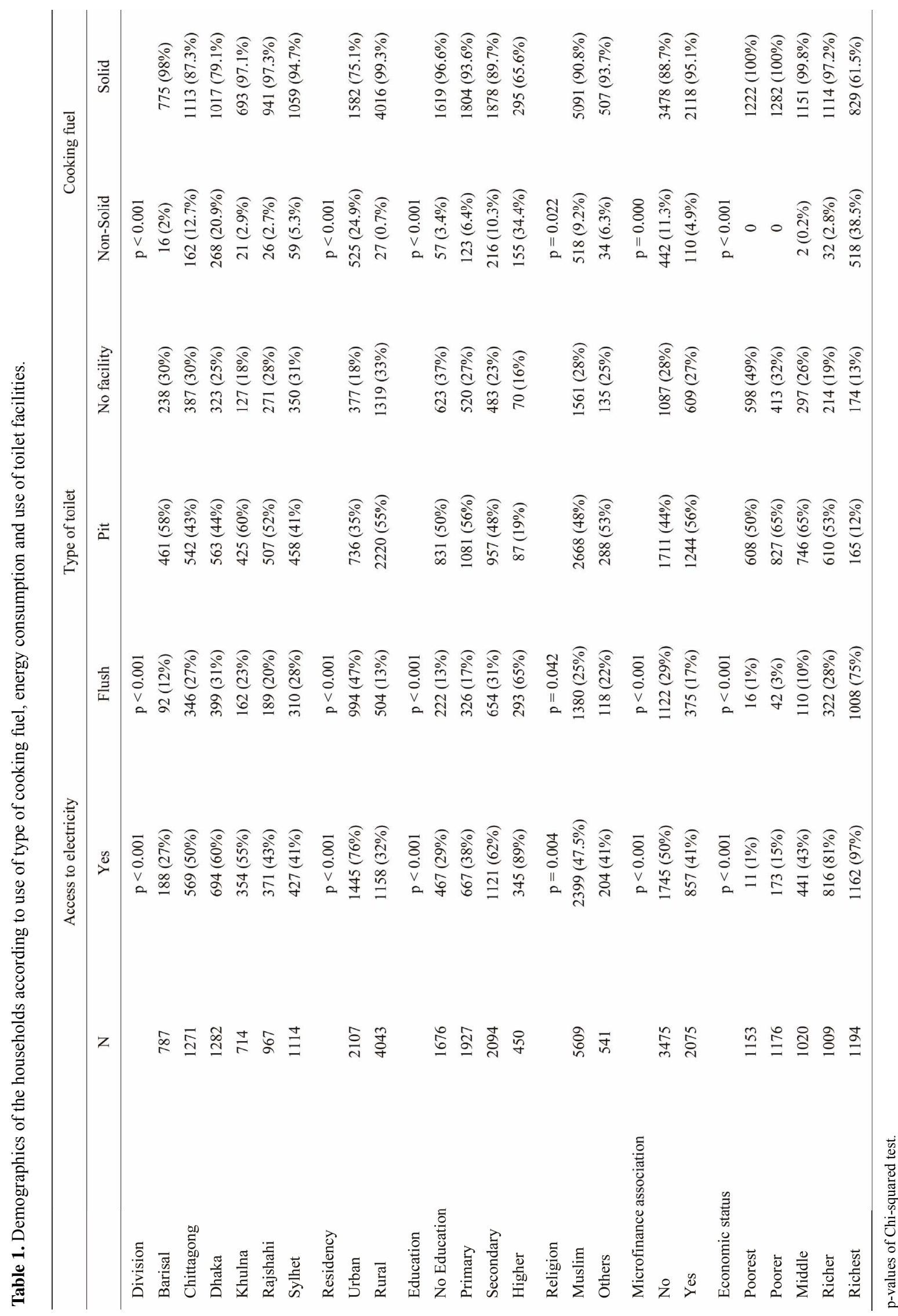




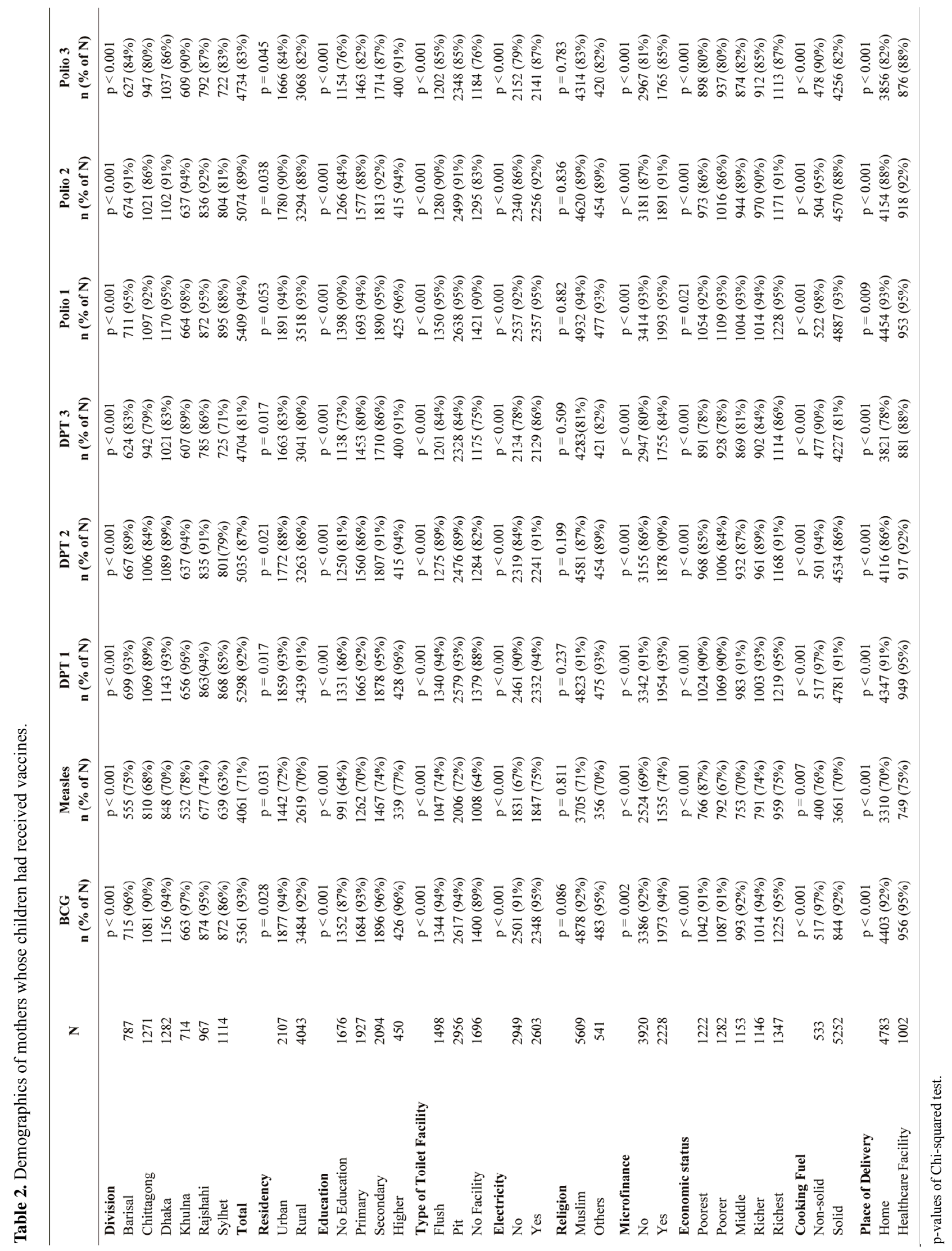




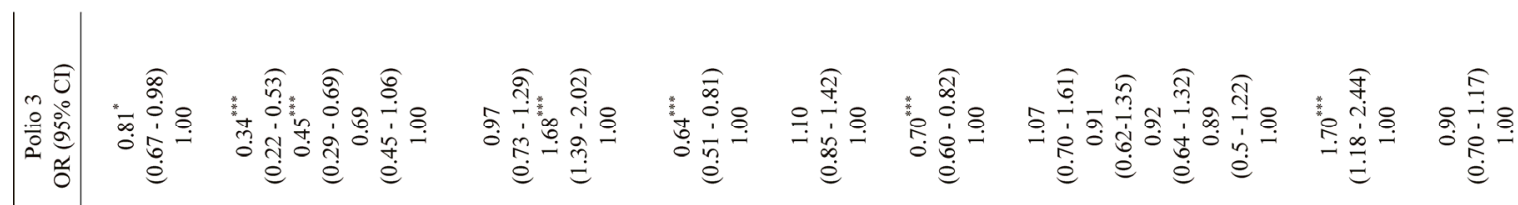

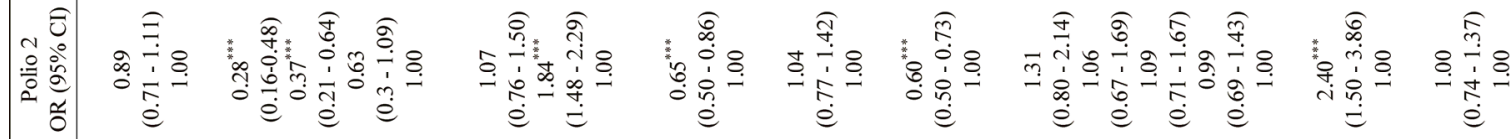

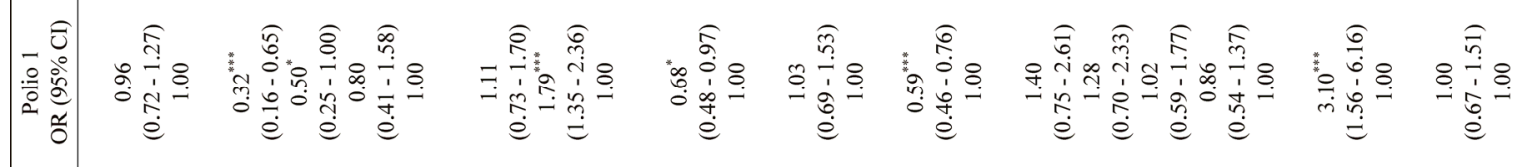

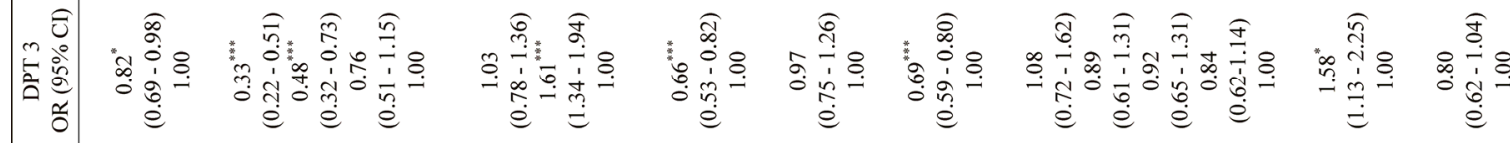

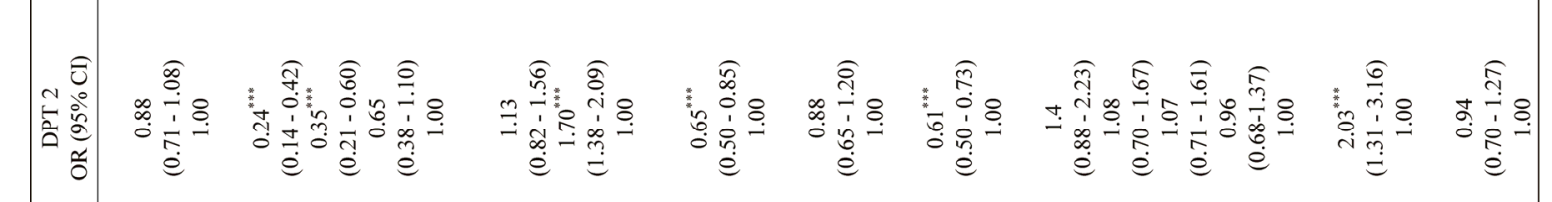

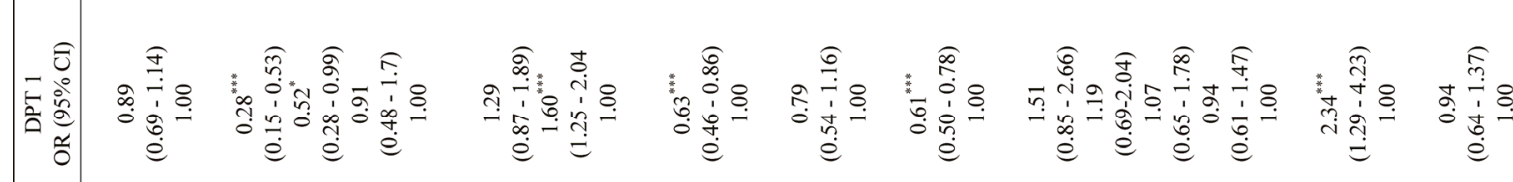

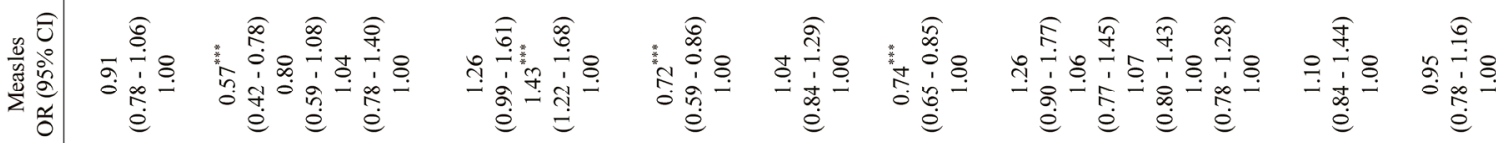

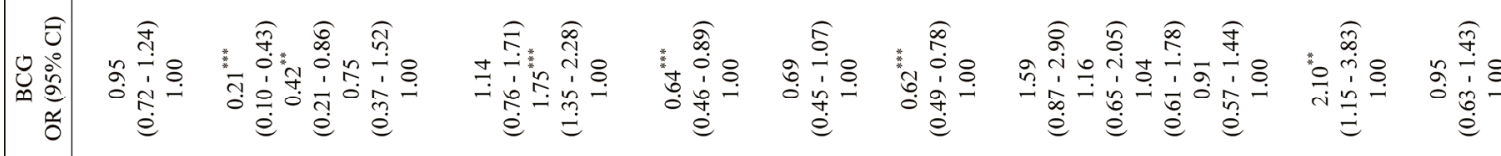

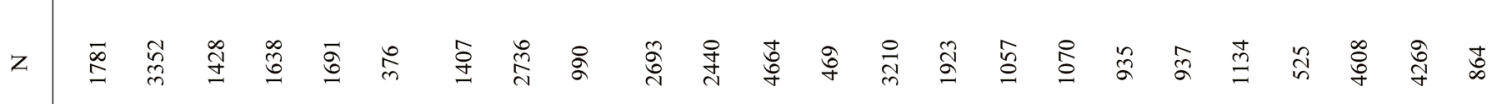


Table 4. Multivariate logistic regression of non-vaccinated children according to maternal and household characteristics.

\begin{tabular}{|c|c|c|}
\hline & $\mathrm{N}$ & $\begin{array}{l}\text { Non-vaccinated children } \\
\text { OR }(95 \% \mathrm{CI})\end{array}$ \\
\hline \multicolumn{3}{|l|}{ Residency } \\
\hline Urban & 1781 & $1.09(0.93-1.28)$ \\
\hline Rural & 3352 & 1.00 \\
\hline \multicolumn{3}{|l|}{ Education } \\
\hline No education & 1428 & $1.60(1.18-2.18)^{* *}$ \\
\hline Primary & 1638 & $1.28(0.95-1.72)$ \\
\hline Secondary & 1691 & $1.05(0.80-1.39)$ \\
\hline Higher & 376 & 1.00 \\
\hline \multicolumn{3}{|l|}{ Type of toilet facility } \\
\hline Flush & 1407 & $0.82(0.54-1.04)$ \\
\hline Pit & 2736 & $0.70(0.60-0.83)^{* * *}$ \\
\hline No facility & 990 & 1.00 \\
\hline \multicolumn{3}{|l|}{ Electricity } \\
\hline No & 2693 & $1.39(1.15-1.68)^{* * *}$ \\
\hline Yes & 2440 & 1.00 \\
\hline \multicolumn{3}{|l|}{ Religion } \\
\hline Muslim & 4664 & $0.96(0.77-1.19)$ \\
\hline Others & 469 & 1.00 \\
\hline \multicolumn{3}{|l|}{ Microfinance } \\
\hline No & 3210 & $1.38(1.21-1.57)^{* * *}$ \\
\hline Yes & 1923 & 1.00 \\
\hline \multicolumn{3}{|l|}{ Wealth } \\
\hline Poorest & 1057 & $0.86(0.62-1.21)$ \\
\hline Poorer & 1070 & $1.06(0.77-1.45)$ \\
\hline Middle & 935 & $1.01(0.76-1.35)$ \\
\hline Richer & 937 & $1.10(0.86-1.40)$ \\
\hline Richest & 1134 & 1.00 \\
\hline \multicolumn{3}{|l|}{ Cooking fuel } \\
\hline Non-solid & 525 & $0.90(0.69-1.17)$ \\
\hline Solid & 4608 & 1.00 \\
\hline \multicolumn{3}{|l|}{ Place of delivery } \\
\hline Home & 4269 & $1.08(0.89-1.32)$ \\
\hline Healthcare facility & 864 & 1.00 \\
\hline
\end{tabular}

OR-Odds Ratio, The contrast category is denoted with $\mathrm{OR}=1.00,{ }^{* * *} \mathrm{p} \leq$ $0.001,{ }^{* *} \mathrm{p} \leq 0.01,{ }^{*} \mathrm{p} \leq 0.05$.

$\{\mathrm{OR}=0.74 ; \mathrm{p}<0.001\}, \mathrm{DPT} 3\{\mathrm{OR}=0.69 ; \mathrm{p}<0.001\}$ and Polio3 $\{\mathrm{OR}=0.70 ; \mathrm{p}<0.001\}$ vaccines. Children in households using non-solid cooking fuel had higher odds of being vaccinated than children in households that used solid cooking fuel. Those which used non-solid cooking fuel had lower odds of being vaccinated against BCG $\{\mathrm{OR}=0.5 ; \mathrm{p}<0.01\}, 50 \%$ more likely for DPT3 $\{\mathrm{OR}=$ $1.58 ; \mathrm{p}<0.05\}$ and almost twice the odds to vaccinate for Polio3 $\{\mathrm{OR}=1.7$; $<<0.001\}$ (Table 3).

Results of the multivariate regression of non-vaccinated children according to maternal and household characteristics are presented in Table 4. Children whose mothers had no education had lower odds of having received complete immunisation coverage than those whose mother had a higher education $\{\mathrm{OR}=1.60 ; \mathrm{p}<$ $0.01\}$.

Households containing a pit facility had lower odds of having completely vaccinated children $\{O R=0.70 ; p<$ $0.001\}$ and children living in households without access to electricity had lower odds of having received complete vaccination coverage $\{\mathrm{OR}=1.39 ; \mathrm{p}<0.001\}$. Children whose mothers were not part of a microfinance group had lower odds of receiving complete vaccinations $\{O R$ $=1.38 ; \mathrm{p}<0.001\}$.

\section{DISCUSSION}

In this study we have examined predisposing factors associated with higher rates of immunisation. The immunisation coverage was higher for children whose mothers were more educated and had higher incomes [23]. Our study shows that households using electricity, households with access to flush toilets and households with mothers participating in microfinance programs were more likely to have their children completely vaccinated. The current findings reflect that, irrespective of need, children of higher economic or educational groups are more likely to be vaccinated. Also, our study highlights the fact that full immunisation coverage is still lacking in Bangladesh. To the best of the authors' knowledge this is the first time such household characteristics for child immunisation coverage have been identified.

Similar to the study by Rahman et al., we found that children with mothers of higher education or higher wealth status were more likely to be immunised [15]. In contrast to Rahman et al. our study did not find substantial differences in vaccination rates among children in urban and rural areas. Consistent with other studies [7,27-31], we found that the mother's education is important for the acceptance of complete vaccination.

This study was based on national statistics rather than focusing on one or just a few areas of the country. By using a nationally representative sample this study achieved a more accurate representation of the situation. There are a few limitations that need to be acknowledged regarding the present study. This study is a cross-sectional analysis and it is not possible to assign causality. The current study has an advantage of eliminating the limitation of recall bias through validating with vaccination cards. The method of obtaining immunisation status through recall interview is not effective. Ensuring the 
availability of vaccination cards with mothers for inspection are recommended for obtaining accurate estimation of vaccine coverage [32]. We have used the same for collecting immunisation data.

Despite the increase in healthcare services and the various immunisation initiatives in Bangladesh, complete immunisation coverage for children under one year of age continues to be inadequate. Since households without electricity and/or toilet facilities, and households with mothers who were not part of a microfinance group were less likely to immunise their children, policy makers should target future interventions to households indicating aforementioned poverty related risk factors. In absence of adequate health staff, it is difficult to visit every house to check the immunisation card. Some visible physical characteristics of the households, such as use of non-electric lighting and use of solid fuels can be used to identify the non-immunised children. At the neighbourhood level it is easy to identify those visible physical household characteristics. These variables can help better identify households with low full immunisation coverage. Mass media promotion programs can be used to educate mothers about the importance of full immunisation, and vaccines should be made not only available, but also affordable throughout the country. Future research could help profile PSUs in which these characteristics predominantly occur and subsequently emphasis the importance of tailoring media and education programs to these areas and their needs.

\section{ACKNOWLEDGEMENTS}

Measures DHS for collecting the data and permitting to use for scientific publications.

\section{REFERENCES}

[1] World Bank (2012) Public health at a glance: Immunization. http://go.worldbank.org/A0E6J0XVO0

[2] Jamil, K., Bhuiya, A., Streatfield, K. and Chakrabarty, N. (1999) The immunization programme in Bangladesh: Impressive gains in coverage, but gaps remain. Health Policy Plan, 14, 49-58. doi:10.1093/heapol/14.1.49

[3] Streefland, P., Chowdhury, A.M.R. and Ramos-Jimenez, P. (1999) Patterns of vaccination acceptance. Social Science \& Medicine, 49, 1705-1716. doi:10.1016/S0277-9536(99)00239-7

[4] Odusanya, O.O., Alufohai, E.F., Meurice, F.P. and Ahonkhai, V.I. (2008) Determinants of vaccination coverage in rural Nigeria. BMC Public Health, 8, 381. doi:10.1186/1471-2458-8-381

[5] National Institute of Population Research and Training (2007) Bangladesh demographic and health survey. Dhaka, Bangladesh and Calverton, 2007.

[6] Perry, H., Weierbach, R., El-Arifeen, S. and Hossain, I. A.
(1998) Comprehensive assessment of the quality of immunization services in one major area of Dhaka City, Bangladesh. Tropical Medicine \& International Health, 3 , 981-992. doi:10.1046/j.1365-3156.1998.00333.x

[7] Bangladesh (2009) EPI factsheet. www.searo.who.int/vaccine/LinkFiles/EPI2009/Banglade sh09.pdf

[8] Bhuiya, A., Bhuiya, I. and Chowdhury, M. (1995) Factors affecting acceptance of immunization among children in rural Bangladesh. Health Policy and Planning, 10, 304312. doi:10.1093/heapol/10.3.304

[9] Khan, M.M., Krämer, A., Khandoker, A., Prüfer-Krämer, L. and Islam, A. (2011) Trends in sociodemographic and health-related indicators in Bangladesh, 1993-2007: Will inequities persist? Bulletin of the World Health Organization, 89, 583-592. doi:10.2471/BLT.11.087429

[10] SEARO (2011) Country health profile. http://ban.searo.who.int/EN/Section28.htm

[11] Rahman, M., Banerjee, M., Rahman, M. and Akhter, F.U. (2006) Vaccination status of tribal mothers and their under five children. Mymensingh Medical Journal, 15, 5557.

[12] Jha, N., Kannan, A.T., Paudel, I.S. and Niraula, S. (2001) EPI vaccination in Nepal. The Southeast Asian Journal of Tropical Medicine and Public Health, 32, 547-552.

[13] CDC (2012) Vaccines safety. www.cdc.gov/vaccines/pubs/pinkbook/downloads/safety. pdf

[14] CDC (2012) Understanding how vaccines work. www.cdc.gov/vaccines/spec-grps/hcp/downloads/vacsafeunderstand-color-office.pdf

[15] Rahman, M. and Obaida-Nasrin, S. (2010) Factors affecting acceptance of completeimmunization coverage of children under five years in rural Bangladesh. Saludpública de México, 52, 134-140. doi:10.1590/S0036-36342010000200005

[16] Khan, M.N., Rahman, M.L., AwalMiah, A., Islam, M.S., Musa, S.A. and Tofail, F. (2005) Vaccination coverage survey in Dhaka District. Bangladesh Medical Research Council Bulletin, 31, 46-53.

[17] Chowdhury, A.M., Bhuiya, A., Mahmud, S., Abdus Salam, A.K. and Karim, F. (2003) Immunization divide: Who do get vaccinated in Bangladesh? Journal of Health, Рориlation, and Nutrition, 21, 193-204.

[18] Rahman, M., Islam, M.A. and Mahalanabis, D. (1995) Mother's knowledge about vaccine preventable diseases and immunization coverage in a population with high rate of illiteracy. Journal of Tropical Pediatrics, 41, 376-378.

[19] Halla, A. (2004) Vaccination and child mortality. Lancet, 364, 2156-2157. doi:10.1016/S0140-6736(04)17604-6

[20] Sanou, A., Simboro, S., Kouyaté, B., Dugas, M., Graham, J. and Bibeau, G. (2009) Assessment of factorsassociated with completeimmunizationcoverage in children aged 12 23 months: A cross-sectionalstudy in Nounadistrict, Burkina Faso. BMC International Health \& Human Rights, 9, S10. doi:10.1186/1472-698X-9-S1-S10

[21] Nath, B., Singh, J.V., Awasthi, S., Bhushan, V., et al. (2007) A study on determinants of immunization cover- 
age among 12 - 23 months old children in urban slums of Lucknow District, India. Indian Journal of Medical Sciences, 61, 598-606. doi:10.4103/0019-5359.37046

[22] Bitragunta, S., Murhekar, M.V., Hutin, Y.J., Penumur, P.P. and Gupte, M.D. (2008) Persistence of Diphtheria, Hyderabad, India, 2003-2006. Emerging Infectious Diseases, 14, 1144-1146. doi:10.3201/eid1407.071167

[23] Dasgupta, S., Huq, M., Khaliquzzaman, M., Pandey K. and Wheeler, D. (2006) Indoor air quality for poor families: New evidence from Bangladesh. Indoor Air, 16, 426-444. doi:10.1111/j.1600-0668.2006.00436.x

[24] Dherani, M., Pope, D., Mascarenhas, M., Smith, K.R., Weber, M. and Bruce, N. (2008) Indoor air pollution from unprocessed solid fuel use and pneumonia risk in children aged under five years: A systematic review and metaanalysis. Bulletin of the World Health Organization, 86, 390-398. doi:10.2471/BLT.07.044529

[25] Bassani, D.G., Jha, P., Dhingra, N. and Kumar, R. (2010) Child mortality from solid-fuel use in India: A nationallyrepresentative case-control study. BMC Public Health, 17, 491.

[26] Rutstein, S.O. and Johnson, K. (2004) The DHS wealth index. DHS Comparative Reports No. 6, Calverton, 2004.

[27] Phukan, R.K., Barman, M.P. and Mahanta, J. (2009) Fac- tors associated with immunization coverage of children in Assam, India: Over the first year of life. Journal of Tropical Pediatrics, 55, 249-252. doi:10.1093/tropej/fmn025

[28] Ibnouf, A.H., Van den Borne, H.W. and Maarse, J.A.M. (2007) Factors influencing immunization coverage among children under five years of age in Khartoum State, Sudan. South African Journal of Family Practice, 49, 14.

[29] Brugha, R. and Kevany, J. (1995) Immunization determinants in the eastern region of Ghana. Health Policy and Planning, 10, 312-318. doi:10.1093/heapol/10.3.312

[30] Parashar, S. (2005) Moving beyond the mother-child dyad: Women's education, child immunization, and the importance of context in rural India. Social Science \& Medicine, 61, 989-1000. doi:10.1016/j.socscimed.2004.12.023

[31] Elliott, C. and Farmer, K. (2006) Immunization status of children under 7 years in the Vikas Nagar area, North India. Child Care Health and Development, 32, 415-421. doi:10.1111/j.1365-2214.2006.00623.x

[32] Ramakrishnan, R., Rao, T.V., Sundaramoorthy, L. and Joshua, V. (1999) Magnitude of recall bias in the estimation of immunization coverage and its determinants. Indian Journal of Child Health, 36, 881-885. 